\title{
A Critical look at the Evidence for and Against Epinephrine use in the toe - A Review
}

\author{
Kevin D. Driscoll, DPM and Mohammed K. Hassan, DPM* \\ East Liverpool City Hospital, Medical Education Department \\ *Corresponding author: Mohammed K Hassan, Medical Education, East Liverpool City Hospital, 425 W 5th St, East Liverpool, OH \\ 43920
}

\begin{tabular}{|c|c|}
\hline ARTICLE INFO & ABSTRACT \\
\hline $\begin{array}{l}\text { Received: 幽 September 25, } 2019 \\
\text { Published: 幽October 01, } 2019\end{array}$ & $\begin{array}{l}\text { Digital block using various anesthetic against exists for the toes. Often the use of } \\
\text { anesthetic agents such and lidocaine, marcaine are available with epinephrine. The } \\
\text { presence of epinephrine confers the anesthesia agents some added benefits. It acts as }\end{array}$ \\
\hline $\begin{array}{l}\text { Citation: Kevin D. Driscoll, DPM, Mo- } \\
\text { hammed K. Hassan, DPM. A Critical look } \\
\text { at the Evidence for and Against Epineph- } \\
\text { rine use in the toe - A Review. Biomed } \\
\text { J Sci \& Tech Res 21(4)-2019. BJSTR. } \\
\text { MS.ID.003640. }\end{array}$ & $\begin{array}{l}\text { a vasoconstrictor to local anesthetic agents, slows systemic absorption, prolongs the } \\
\text { anesthetic effect, reduces the bleeding in the surgical field. Some surgeons continue to } \\
\text { believe that epinephrine should not be used in the toes. Often this belief stems from the } \\
\text { fact that epinephrine could potentially cause prolonged vasoconstriction in the tissues } \\
\text { leading to a lack of adequate blood supply to the toe. Such an effect could lead to necrosis } \\
\text { and tissue death. However, a literature review on the topic did not yield any concrete } \\
\text { evidence to indicate that epinephrine is the cause of tissue necrosis and thus should not } \\
\text { be used as an anesthetic agent in the toe. }\end{array}$ \\
\hline
\end{tabular}

\section{Introduction}

When fingers or toes are injured, a digital block is commonly used to block the nerves to these digits, anesthetizing the digit to allow for more effective medical care [1]. Digital blocks typically avoid any systemic complications that may arise from general anesthesia or other desensitizing options [2]. Epinephrine used with local anesthetic presents positive vasoconstrictive effects as part of the digital block procedure; however, it has not historically been used for this purpose due to early research indicating an increased incidence in tissue damage and gangrene [3]. Although recent research indicates this older body of evidence is inaccurate, many continue to advise against adding epinephrine to local anesthetic for digital block use [4]. A critical evaluation of the evidence regarding injected epinephrine use in digital blocking in the toe indicates that the benefits outweigh potential concerns, which have little evidence in modern investigations.

\section{Discussion}

The historical root of recommendations against epinephrine use with local anesthetic lies in research conducted prior to 1950, with the results of this research included in medical texts and perpetuating views that prolonged vasoconstriction of arteries from epinephrine resulted in a lack of adequate blood supply and could cause permanent tissue damage [2]. However, investigations into these historic studies and more recent examination of combined epinephrine and anesthesia use in digital blocking indicates epinephrine use was not likely the cause of tissue death as previously reported [4,5] considered 48 cases of digital necrosis located in an exhaustive review of literature from 1880 through 2000 and reported that only 21 of these cases used injected epinephrine, with more cases of digital necrosis resulting from anesthesia alone. In addition, the procaine used in these cases was relatively unregulated and had variable quality and toxicity, more likely leading to the tissue death reported.

Epinephrine was also diluted manually during this time, increasing the possibility of inappropriate dosing [4,5] came to similar conclusions through a review of cases from 1966 through 2006, identifying three research studies and four literature reviews on injected epinephrine use and digital necrosis in digital blocking. They noted similar issues with older research and concluded based on more current investigations that epinephrine was advantageous, improving anesthesia duration and hemostasis while decreasing pain and the amount of anesthesia required [5]. These older studies therefore appear to attribute tissue damage to reduced blood flow and identify epinephrine as the cause of this restriction, although there is little support to indicate epinephrine use was causal in 
any necrosis. Although cause for previous recommendations is identified in these evaluations of historic research, additional investigation in any benefits and/or injury caused by epinephrine in more recent studies is also warranted. As the concerns regarding epinephrine center on prolonged vasoconstriction [3] used color Doppler ultrasonography both prior to digital blocking and at intervals during digit surgery and recovery to investigate the actual impact of epinephrine.

Of the 24 patients undergoing this blood flow monitoring, none had restriction long enough to result in tissue damage, and all returned to normal circulation within 90 minutes from the epinephrine injection, and most returned within an hour, indicating that epinephrine vasoconstriction did not result in tissue damage [3]. Further investigating the effects of epinephrine use in digital blocking, [2] found that in 3,110 cases of digital block to the fingers or hand in which an anesthesia and epinephrine combined injection was used, no tissue loss was reported, and vasoconstriction reversed with time, not requiring use of phentolamine to restore blood flow. [6] report similar results with the use of epinephrine in the feet and toes, with no adverse effects in 22 patients studied; in addition, those in the epinephrine group had reduced anesthesia needs and drainage issues compared to the control group, who were administered anesthesia alone. The majority of this research does involve digital blocking of the fingers and hand, rather than the toes. However, [6] focused exclusively on the toes as their study was limited to patients undergoing surgery for ingrown toenails, and Waterbrook, [3] included both fingers and toes in their investigation.

The use of epinephrine in combination with injected anesthesia is administered similarly regardless of the type of digit involved, and while the resulting vasoconstriction can be greater in patients with circulation issues, as typically feet and toes are more affected by circulatory conditions than fingers and hands, none of the literature reviewed indicated concerns regarding digit variance, and the study most commonly cited regarding return to normal blood flow, [4] included both types of digits in their monitoring. In addition, historic research studies were conducted in contexts before the availability of phentolamine, an alpha-blocker which acts as a vasoconstriction antagonist and reverses the effects of epinephrine [6]. Availability of phentolamine provides the medical team a means to increase blood flow should any prolonged constriction occur and thereby prevent potential tissue damage, an option not available in historic medical practice [6]. This review indicates that use of injected epinephrine poses limited to no risk for tissue damage when used in the toe but does provide several benefits both during surgery and in post-surgical recovery. Recommendations against epinephrine are based on outdated information, which is contradicted by more modern and thorough investigations.

\section{References}

1. Van Niekerk I (2016) Digital nerve block. Canadian Journal of Rural Medicine 21(3): 84 .

2. Lalonde D, Bell M, Benoit P, Sparkes G, Denkler D, et al. (2005) A Multicenter Prospective Study of 3,110 Consecutive Cases of Elective Epinephrine Use in the Fingers and Hand: The Dalhousie Project Clinical Phase. The Journal of Hand Surgery 30A (5): 1061-1067.

3. Altinyazar HC, Zdemir H, Koca R, Hosnuter B, Demirel CB, et al. (2004) Epinephrine in Digital Block: Color Doppler Flow Imaging. Dermatologic Surgery 30: 508-511.

4. Thomson CJ, Lalonde DH, Denkler KA, Feicht AJ (2007) A Critical Look at the Evidence for and against Elective Epinephrine Use in the Finger. Plastic Reconstructive Surgery 119(1): 260-266.

5. Waterbrook AL, Germann CA, Southall JC (2007) Is Epinephrine Harmful When Used with Anesthetics for Digital Nerve Blocks? Annals of Emergency Medicine 50: 472-475.

6. Altinyazar H, Demirel, Koca R, Hosnuter B (2010) Digital Block with and Without Epinephrine During Chemical Matricectomy with Phenol. Dermatologic Surgery 36: 1568-1571.
ISSN: 2574-1241

\section{DOI: 10.26717/BJSTR.2019.21.003640}

Mohammed K Hassan. Biomed J Sci \& Tech Res

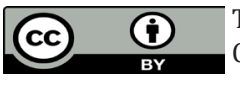

This work is licensed under Creative Commons Attribution 4.0 License

Submission Link: https://biomedres.us/submit-manuscript.php

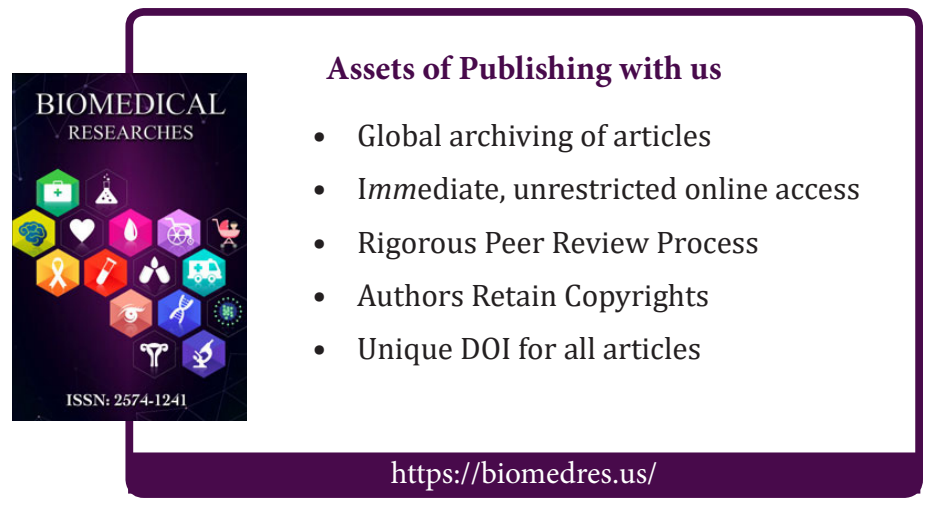

